\title{
Bringing Production Back into Development: An introduction
}

\author{
Ha-Joon Chang ${ }^{1} \cdot$ Antonio Andreoni ${ }^{2,3}$
}

Accepted: 12 January 2021 / Published online: 2 March 2021

(c) European Association of Development Research and Training Institutes (EADI) 2021

\begin{abstract}
Production was at the heart of economics from the days of Classical economics. However, with the rise of Neoclassical economics in the late 19th century, production has lost its status as the ultimate interest of economics. Several opportunities for fruitful integration of alternative streams of economics research-Evolutionary, Structuralist and Keynesian in particular-have been also missed. Even the humanist approaches to development, such as Sen's Human Capability Approach, paid little attention to the domain of production. In this article, we argue that the fragmentation of the production-centred paradigm has weakened both academic research and policy-making related to economic development. We introduce and discuss eight articles developed around the special issue theme of Bringing Production Back into Development. We argue that a renewed 'productionist' agenda is essential to address the structural challenges faced by developing countries, even more so after the revelation of structural weaknesses by the pandemic.
\end{abstract}

Keywords Production · Productive capabilities · Human capability approach · Industrial policy $\cdot$ Economic development

\section{Resume}

La production était au cœur de l'économie depuis l'époque de l'économie classique. Cependant, avec l'essor de l'économie néoclassique à la fin du XIXe siècle, la production a perdu son statut de centre d'intérêt ultime de l'économie. Ont également été manquées plusieurs opportunités d'intégration fructueuse avec des courants al-

\section{Ha-Joon Chang}

hjc1001@cam.ac.uk

Antonio Andreoni

a.andreoni@ucl.ac.uk

1 Faculty of Economics and Centre of Development Studies, University of Cambridge, Cambridge, UK

2 Institute for Innovation and Public Purpose, University College London, London, UK

3 South African Research Chair in Industrial Development, University of Johannesburg, Johannesburg, South Africa 
ternatifs de recherche en économie, en particulier l'évolutionnisme, le structuralisme et le keynésianisme. Même les approches humanistes du développement, telles que l'approche par les capacités humaines de Sen, n'accordaient que peu d'attention au domaine de la production. Dans cet article, nous soutenons que la fragmentation du paradigme centré sur la production a affaibli à la fois la recherche universitaire et l'élaboration des politiques liées au développement économique. Nous présentons et discutons de huit articles développés autour du thème de ce numéro spécial, « Le retour de la production au sein du développement ». Nous soutenons qu' un programme «productiviste» renouvelé est essentiel pour relever les défis structurels auxquels sont confrontés les pays en développement, et plus encore après la dynamique accélérée insufflée par la pandémie.

\section{Introduction}

Production was at the heart of economics from the beginning. Even before the Classical Political Economists of the XVIII and XIX century, The Tableau Economique of Francois Quesnay modelled the economy around production interdependencies, and the Physiocrats recognised agriculture production as the ultimate source of wealth. With the advent of industrialisation, both Adam Smith and Karl Marx understood economic development as a consequence of changes in the organisation of production (Smith's work on division of labour and Marx's work on the rise of the factory system), even going as far as defining their respective 'stages of development' in terms of the productive system. Alexander Hamilton's theory of infant industry protection (and the elaboration by his followers, especially Friedrich List) was ultimately less about trade but more about production; how to create the space, through tariff protection and other measures, in which young producers in economically backward nations can develop their productive capabilities (Chang 2002; Lin and Chang 2009).

However, in the late 19th century, with the marginalist revolution and the following rise of Neoclassical economics, with its almost exclusive focus on market exchanges, scarce resources and consumption, production lost its status as the ultimate interest of economics. The disappearance of production from the centre stage of economics was due to the rejection within Neoclassical economics of the fundamental analytical challenges posed by learning, production and innovation dynamics within an equilibrium framework (Kaldor 1972). Other factors contributed to the weakening of the 'production-centred paradigm' as well. Specifically, several opportunities for fruitful integration of different streams of economics research outside Neoclassical economics were missed. Over time, this led to the fragmentation of the 'production-centred paradigm' and its marginalisation within economics, despite significant advancements especially in Evolutionary and Structuralist economics (Nelson and Winter 1982; Dosi 1982; Freeman 1982; Pavitt 1984; Pasinetti 2007). Even development economics, a bastion of production-centred research until the 1970 s, capitulated over the 1980s and 1990s as a result of the re-conceptualisation of 'development as freedom' (Sen 1999; Lall 2001; Chang 2010; Andreoni and Chang 2017). 


\section{Production: A Tale of Marginalisation and Missed Opportunities}

Neoclassical economics moved economics away from its 'production-centred paradigm' towards an 'exchange-centred paradigm', with its main purpose becoming the study of "human behaviour as a relationship between ends and scarce means which have alternative uses" (Robbins 1935, p. 16). Production was reduced to an elementary functional form suitable to equilibrium economics, preventing us from understanding the evolutionary character of the capitalist process as pointed out by Joseph Schumpeter. "The fundamental impulses that sets and keeps the capitalist engine in motion comes from the new consumers' goods, the new methods of production or transportation, the new markets, the new forms of industrial organization that capitalist enterprise creates" (Schumpeter 1942, p. 83).

The birth of Keynesian economics, with its focus on aggregate output and employment, in the 1930s also shifted economists' attention away from the microstructural dynamics of learning, productive capabilities development and organisational changes in industry (Andreoni 2014; Andreoni and Scazzieri 2014). Since the late 1950 s, seminal contributions on the theory of the firm and industrial organisations were developed by Edith Penrose, Herbert Simon, George Richardson, Nicholas Georgescu-Roegen, Nathan Rosenberg, Alfred Chandler and William Lazonick. However, these contributions were not acknowledged and integrated into Keynesian economics, and were almost completely ignored by Neoclassical economics. Business history, management studies and organisational science became the new houses of these production-centred research streams and continued developing mainly outside economics. This was perhaps the first missed opportunity of integrating Keynesian and Structural economics with production-centred contributions on firms, capabilities and innovation dynamics. ${ }^{1}$

Production came back to the centre stage of (at least one part of) economics, with the rise of development economics in the 1940s and the 1950s. In the early days of development economics, economic development was essentially seen as a process of transforming the productive structure - and the underlying productive capabilitiesof an economy. Rosenstein-Rodan's Big Push and Albert Hirschman's Linkages advanced two alternative growth models-balanced vs unbalanced-but both were based on a theory of structural dynamics deriving from production interdependences among different sectors (see Toner 1999 for a review). Latin American structuralism and dependency theorists; including Celso Furtado, Raul Prebisch and Hans Singer-and Hollis Chenery's two-gap model were predicated on the fundamental economic constraints (in terms of balance of payments, technological dependence) generated by the developing countries' inability to produce capital goods.

\footnotetext{
1 Notable exceptions are Nicholas Kaldor and Luigi Pasinetti, however, in both cases their approach to production was one from the macro to the meso (sectoral level), and an approach that remained largely agnostic of the micro (firms and capabilities). When concepts of producer learning (Pasinetti) or increasing returns (Kaldor) were developed and integrated into multi-sectoral models of economic growth, the micro-dynamics of learning and increasing returns remained black-box concepts.
} 
Starting from the mid-1970s, Sanjaya Lall, Martin Bell, Jorge Katz, Larry Westphal, Linsu Kim and Martin Fransman emphasised the importance of building technological capabilities in developing countries. Hirschman and Moses Abramovitz also pointed out how organisational and social capabilities are key for productive transformation and for explaining economic catching-up. The establishment of the link between productive capabilities embedded in productive organisations and broader institutions of production created the basis for the development of the national system of innovation approach in the work of Christopher Freeman, BengÅke Lundvall and Richard Nelson. These contributions developed alongside contributions in evolutionary economics, starting with the seminal works of Richard Nelson, Sidney Winter and Giovanni Dosi. However, with a few exceptions, these contributions remained largely disconnected from both theoretical and applied research in development economics, the political economy of industrialisation and the role of the state. The lack of a systematic dialogue between research streams in development economics and evolutionary economics, as well as between evolutionary economics and structuralist economics further contributed to the fragmentation of the production-centred paradigm. ${ }^{2}$

Since the 1980s, with the increasing dominance of Neoclassical economics even in development economics, the market - the domain of exchange-was elevated to the ultimate (or even sole) domain of the economy. Conforming to market signals, summarised in the slogan 'get the prices right', was seen as the best way for economic development. Transformation in the domain of production, if it was ever contemplated, was assumed to follow automatically from changes in market incentives. Indeed, the vast majority of developing countries were pushed away from their aspirations for a productive transformation of the economy with the imposition of the neo-liberal structural adjustment programs (SAPs) by the World Bank and the International Monetary Fund (Amsden 1997). Conforming to comparative advantage and refraining from industrial policy-making (and other state interference in the market) became the key policy propositions of the neo-liberal agenda (for a collection of critical approaches to development economics see Reinert et al. 2018; Nissanke and Ocampo 2019).

Even when the 'market fundamentalism' of the 1980s and the first half of the 1990s started to wane, the alternatives proposed all paid little attention to the domain of production. Amartya Sen's capabilities approach-and the Millennium Development Goals as its manifestation in the policy-making world-focussed on capabilities of individuals as consumers and citizens, even though it could have incorporated individual capabilities as workers and the collective capabilities in the domain of production (as well as in other domains). Microfinance, the darling of the development community in the late 1990s and the early 2000s, while ostensibly promoting escape poverty through business activities, had no understanding of how productive capabilities are created and accumulated and thus thought poverty reduction and economic development could be achieved through micro-enterprises that involve

\footnotetext{
${ }^{2}$ For a comparative analysis of the intellectual origins and analytical crossovers of the two approaches see (Scazzieri 2019).
} 
minimal skills and capital. The conditional cash transfer (CCT) programmes that were presented as a more 'progressive' (and more 'feminist') alternative to microfinance was basically focussed on individuals as consumers and citizens.

\section{Why We Need to Bring Production Back}

While the mainstream of the development discourse was looking the other way, there have been several developments in the last few decades, which have increasingly made people realise the need to bring production back into the development discourse, especially development economics.

First, the so-called East Asian economic miracle (especially in Japan, South Korea and Taiwan) between the 1960s and the 1980s and subsequently China's economic miracle since the 1980s have shown the critical importance of the transformation of the productive structure and the industrial policy that made such transformations possible (Amsden 1989; Wade 1990; Chang 1994). ${ }^{3}$ What is most notable about the remarkable economic growths of these economies is not just high rates of growth but that it was based on continuous re-organisation and upgrading of productive capabilities. This growth based on transformation of productive capabilities has made the increases in standards of living in East Asia far more durable than those found in countries that achieved fast growth without a fundamental transformation of such capabilities - such as a discovery of resource bonanza (most oil economies) or an integration into a richer economic zones (e.g. EU accession).

Second, the introduction of neo-liberal trade and industrial policies in developing countries through the SAPs of the World Bank and the IMF in the 1980s and the 1990s, and their subsequent institutionalisation through the establishment of the WTO (World Trade Organization) in 1995, have resulted in 'premature de-industrialisation' among middle-income countries and 'pre-industrial premature de-industrialisation' in several least developed countries. By prematurely exposing the fledgling producers of developing countries to international competition from superior producers from abroad, these policy changes have destroyed the superior productive capabilities that had been emerging in higher productivity industries. As a result, these countries have lost their economic dynamism, become far more vulnerable to external shocks, and seen their people's livelihood becoming much more precarious. Now there is a renewed attention to the importance of the manufacturing sector and the associated knowledge-intensive service activities-not simply its expansion but more importantly the development of productive capabilities within it (Chang and Andreoni 2020).

Third, the expansion and the growing sophistication of the GVCs (global value chains)—not just in manufacturing but also in agriculture and services-since the 1990s (they are not new-they have existed since the 1950s) has shown the importance of a country's place in the global production system in determining not just its standard of living but also its vulnerability and stability (Lema et al. 2018).

\footnotetext{
${ }^{3}$ For a history of economic analysis of industrial policy see (Andreoni and Chang 2019).
} 
Relatedly, the persistence of the so-called 'middle-income trap' in countries that have tried to develop their economies through unconditional participation in GVCs-Mexico, Thailand and (to a lesser extent) Malaysia are the most prominent examples-has made people realise that genuine productive transformation cannot happen without strategic industrial policies that focus on enhancing domestic productive capabilities (Lee 2013). Indeed, middle-income countries face the triple challenges of 'breaking into' the global economy, 'linking up' into global value chains while 'linking back' to the local production system and 'keeping pace' with technological change and innovation (Andreoni and Tregenna 2020).

Fourth, the emergence of new technologies that could bring about a techno-paradigm shift (often contentiously called 'the Fourth Industrial Revolution', or 4IR) robotics, new materials, the digital technologies, bio-technology, and so on-have created both challenges and opportunities for developing countries. The new technologies can offer unique opportunities of 'leap-frogging' for developing countries, as previous generations of paradigm-shifting technologies (e.g. steam power, electricity, electronics) have done. However, it is increasingly being realised that the leap-frogging in this round of techno-paradigm shift requires much more concerted efforts than in the previous eras because of the nature of the technological changes that are going on. It is not that the so-called 4IR technologies are, individually, more 'revolutionary' and thus difficult to master than previous paradigm-shifting technologies. They often are not. However, the current wave of technological changes involves a lot of fusion between different technologies. Managing technological fusion requires 'foundational productive capabilities' - that is, the capabilities to learn new technical and organisational solutions and apply them in creative and flexible ways - that are particularly lacking in developing countries. Given this, it is increasingly recognised that there is an urgent need for finding a way to build such capabilities quickly in the developing world.

Fifth, the challenges of climate change have increased the urgency of the need to achieve a large-scale transformation of the production system, including the energy system this time around (Hallegatte et al. 2016). Even while climate change mitigation and adaptation require significant changes in our consumption pattern, living environment and the transportation system, they cannot be achieved without fundamental transformations in the domain of production - the development of renewable energy technologies, the creation of low-carbon food systems, the development of new materials (that are less carbon-intensive in production, that are lighter and thus save energy in transportation and that help increase energy use efficiency), carbon capture technologies and many others (Fuso Nerini et al. 2016). The need to achieve this wide range of transformations across many areas of production in a very short span of time will stretch human ingenuity and organisational abilities (not just at the firm level but also at the policy level) to an unprecedented degree.

Finally, the global financial crisis of 2008, the increasing financialisation and rapid increase in inequalities in many advanced economies have revealed the social, economic and political vulnerabilities of an economic model centred on market exchanges instead of production relations (Galbraith 2012; Lazonick and Shin 2019). The weaknesses of such model are being even more highlighted by the ongoing socio-economic crises caused by the Covid-19 pandemic (Henson et al. 2020). 
The pandemic has revealed the increasingly precarious nature of employment for many who work in the low-productivity sectors (including many service sectors), the inadequacy of the welfare state for those who do not have stable jobs (of the kinds destroyed in the de-industrialisation process) and the problematic nature of a society excessively based on contingent contracts that are hopeless in the face of a systemic shock. Attention is increasingly drawn on the need to create an economic structure - and the jobs and livelihoods that it contains - that is based on higher and more durable productive capabilities, not just in manufacturing but also in agriculture, mining and services.

In order to understand all these diverse systemic challenges and crises cutting across traditional categorisations of countries, we need to come up with a theoretical framework that puts production at the centre stage. For developing countries, production transformation is central for any development pathway that is inclusive and sustainable. For advanced economies, understanding how production dynamics affect (and are affected by) societal and political changes is critical for developing a social contract that is progressive, inclusive and sustainable.

Bringing production back to the centre, of course, does not mean simply dusting off Marx or reviving 'classical' development economics, à la Rosenstein-Rodan or Hirschman. We need to update the older 'productionist' theories (like Marx's theory of production, the Infant Industry argument, Latin American Structuralism, the Linkages argument) by incorporating the more recent developments in: the capabilities approach to production, technology and innovation; the theories of the firm, industry organisation and GVC; the literature on structural change, economic dynamics and de-industrialisation; the neo-Schumpeterian and the evolutionary literature (especially the National Systems of Innovation literature); the post-1980s literature on industrial policy, especially those approaches focusing on how to achieve inclusive and sustainable development outcomes.

The fragmentation of the production-centred paradigm has weakened both academic research and policy-making related to economic development. This special issue of European Journal of Development Research, is meant to be a contribution to the emerging attempt to bring production back into development in order to overcome these weaknesses. We have collected research articles that use state-of-the-art theoretical developments and empirical evidence to evaluate the recent changes in various aspects of the domain of production with a focus on developing countries.

\section{The contributions in this special issue}

The contributions in this special issue are organised in three main sections: theoretical contributions; country case studies and comparative studies; and finally contributions addressing emerging opportunities and challenges.

The first two articles in this special issue revisits two central research streams in economic development. The first of these two articles re-examines the human capabilities approach, including the approach's profound influences on the dominant global development agenda since the 1980s. The second article critically assesses recent research on the key drivers of structural transformation in open economies, 
that is, the role of trade, linkages and domestic demand. Both contributions offer in-depth analyses of the policy implications of conventional theories in both national and international contexts.

In 'The Missing Dimensions of the Human Capabilities Approach: Collective and Productive', Andreoni, Chang and Estevez (ACE) provide some theoretical discussions on productive capabilities, especially collective productive capabilities, that provide (explicit and implicit) conceptual foundations to other articles in this special issue. Acknowledging the very important contributions of the Human Capabilities Approach (HCA), ACE argue that the HCA neglects two important dimensions of human capabilities - the collective and the productive-despite the fact that the incorporation of these dimensions is a natural extension of the approach. In pointing out the theoretical problems of this neglect and, more importantly, showing how such a neglect has crucially weakened global development agendas, such as the Millennium Development Goals Agenda and the Sustainable Development Goals Agenda, ACE advance a productionist perspective on development, centred around the idea of collective productive capabilities. They argue that bringing production back to the core of the development agenda calls for an integration of the HCA with those contributions that have focussed their attention on the social, economic and institutional processes of learning, centred around productive organisations and systems.

Maria Savona, in her 'Revisiting High Development Theory to explain Business Services Global Value Chains', revisits and integrates two classical approaches to development and trade-that is, Hirschman's approach to linkages and Linder's approach to domestic demand-to offer an alternative interpretation of the emergence of Global Value Chains (GVCs) involving business services (BS). The article reviews the so-called Hirschman Linder Hypothesis (HLH), according to which an adequate 'representative domestic (intermediate) demand' for intermediate inputs (business services in this case) is needed for countries to enter GVCs using such inputs. The systematic review of the quantitative and qualitative empirical evidence in support of the HLH, points to two main results: (i) countries that have a substantial manufacturing core are more likely to participate in BS GVCs, as BS are mainly demanded by the manufacturing sector; (ii) contrary to the popular (implicit) assumption, countries that are specialised in natural resource industries (NRI) also are likely to be part of BS GVCs, as NRI these days generate demands for BS. This implies that a core manufacturing sector is essential for entering BS GVCs but also that NR might not necessarily be a curse, if countries use the demand for BS that it generates and diversify into BS and eventually enter BS GVSs.

The following four articles focus on the dynamics of production transformation and the development of productive capabilities across diverse sectoral value chains and countries. Specifically, these contributions sit at the intersections of different economic dynamics: production upgrading and financialisation; production diversification and competition policy; and productive capabilities upgrading and industrial policy. The first two articles present in-depth country-specific studies (Ghana and South Africa), focusing on key sectors and industry groupings in developing countries (agri-food sector, the metals and machinery sector and the plastics and chemicals sector). The following two articles develop regional comparative analyses 
of productive capabilities development at the sectoral and the firm levels. The first one looks at the automotive sector value chain development for countries across East and South-east Asia (Korea, Malaysia, Thailand and China); the second provides a firm-level quantitative assessment of productive capabilities across countries in the African continent. All four articles assess different factors responsible for the development and the accumulation of productive capabilities across developing and middle-income countries.

In 'Potential for Upgrading in Financialised Agri-Food Chains The Case of Ghanaian Cocoa', Van Huellen \& Abubakar look at the food sector, which many people implicitly assume does not require upgrading of productive capabilities. They examine functional upgrading opportunities for developing and emerging market companies in the context of highly financialised food systems. They point out how an assessment of upgrading potential cannot prescind from the consideration of constraints posed by financialisation at the sectoral level but also in relation to the global financial architecture. With a focus on the Ghanaian cocoa-chocolate sector, they show that financialisation acts as a key limiting factor to upgrading, with contradicting tendencies. First, while outsourcing of non-core activities by transnational corporations (TNCs) that control the cocoa-chocolate GVC has opened some space for cocoa processing in Ghana, further functional upgrading is limited by the financialisation of the leading TNCs and the endogenous power asymmetries along the GVC. Second, the expansion opportunities in the domestic and regional markets are limited by the foreign exchange constraints for Ghana. These tendencies result in a 'middle value-added trap' and call for policy interventions that can allow developing country producers avoid the trap.

In 'Competition, Productive Capabilities and Structural Transformation in Southern Africa', Goga, Mondliwa \& Roberts (GMR) look at the role of competition policy in shaping an economy's productive capabilities. The authors challenge the conventional approach to competition policy in developing countries, pointing out how this powerful regulatory instrument has been mainly used as part of a market liberalisation agenda, rather than to promote economic diversification. Contrasting the neoclassical model of competition with the conception of 'optimal competition' of Amsden and Singh (1994), the article advances a production-centred framework that promotes economic diversification beyond static allocative efficiency principles. With a focus on South Africa, the article does so by investigating the relationship between competitive rivalry, productive investment and the development of capabilities in two key industry groupings, metals and machinery, on the one hand, and plastics and chemicals, on the other. The two sectoral cases show how the optimal competition framework allows a more sophisticated analysis of dynamic rivalry and capabilities development.

In their article, 'Can Industrial Policy Work for Upgrading in the GVC? Local Content Requirement Policy in the Automobile sectors of Malaysia, Thailand and China in comparison with Korea', Lee, Di and Mao (LDM) look at a sector that has arguably seen the most amount of firm efforts at and government supports for productive capabilities upgrading across the world-that is, the automobile sector. They compare the evolution of automotive sectors in Malaysia, Thailand and China with that of Korea by focusing on industrial policy, particularly local 
content requirements (LCRs). By relying on three different measures of upgrading in GVC - the share of domestic (or foreign) value-added in their exports, export orientation (re-exported intermediate imports) and international competitiveness of their intermediate parts (domestic value-added embodied in foreign exports), they find different development pathways and upgrading outcomes. They explain such divergent outcomes in terms of three key interrelated factors, that is, local ownership, disciplines from market competition and firm-level efforts and strategies. The country-specific unfolding of the relationship between these three factors points to the challenges in enforcing effective industrial policy for productive and technological capabilities building and accumulation.

In 'Productive capabilities, innovation and firm performance: evidence from African SMMEs', Avenyo, Kraemer-Mbula and Tregenna (AKT) examine the link between export performance and the evolution of productive capabilities at the firm level. They introduce and deploy firm-level measures of capabilities in African countries and argue that more evidence is required. With a focus on the African continent, the article develops indicators of firm-level productive and technological capabilities and examines their effects on the export performances. Building on the World Bank Enterprise Survey across 29 African countries, the article estimates a censored regression model to find that technological and production capabilities are important drivers of firms' efficiency and competitiveness and affect export performance positively. These findings point to the importance of industrial policies supporting firms' learning efforts in African countries.

In their article, 'Natura non-facit saltus: Challenges and opportunities for digital industrialisation across developing countries', Andreoni, Chang and Labrunie (ACL) examine the implications of the emergence of the so-called 4IR technologies for developing countries. ACL point out that the current discourse on 4IR is often based on poor understanding of the true nature of the phenomenon. Emphasising that many of the so-called 4IR technologies have been around and evolving in the last half a century, ACL argue that what defines 4IR is the fusion of these technologies, rather than the nature of particular individual technologies. Given this, ACL argue that, rather than trying to master particular 4IR technologies, developing countries should first focus on acquiring what they call the foundational capabilities, that is, the capabilities to learn new technical and organisational solutions and apply them in creative and flexible ways to different economic activities. Using this perspective, ACL then discuss in great detail how different 4IR technologies are reshaping existing industries and creating new industries through technological fusion. They also discuss how these changes are affecting the opportunities and the challenges faced by developing countries for industrial development.

In 'Three dimensions of Green Industrial Policy in the context of climate change and sustainable development', Anzolin and Lebdioui look at the issues related to productive capabilities in what is the most pressing challenge of our time-climate change. They contribute to the growing literature on 'green industrial policy' (GIP) by developing a finer analytical framework than what is prevalent. They do this by examining three dimensions of GIP: (i) the consumption-centred dimension; (ii) the firm-level sustainability dimension, (iii) the productionist innovation-driven dimension. This article then applies the framework to an analysis of the GIP of Ecuador. 
Two main findings are highlighted. First, while a greener consumption is necessary, it cannot be achieved without the transformation of productive capabilities that enable green manufacturing and low-carbon innovation. Second, the three dimensions of GIP need to be closely integrated if we are to ensure a coherent and developmental 'green' transition.

The collection of articles in this special issue are diverse in their topics and approaches. There are two conceptual articles, albeit with direct link with real-world policy practices (Andreoni, Chang and Estevez; Savona). There are articles that look at the key developments along different sectors of the economy (Van Huelen and Abubakar; Lee, Di and Mao; Goga, Mondliwa \& Roberts) and the challenges of building firm-level productive capabilities (Avenyo, Kraemer-Mbula and Tregenna). And then there are articles that analyse the emerging paradigmatic challenges, such as the 4IR (Andreoni, Chang and Labrunie) and climate change (Anzolin and Lebdioui). However, there are some common themes that emerge from this diverse collection.

\section{Bringing Production Back into Development: Cross-cutting Themes}

The articles in the special issue highlight the importance of productive capabilities upgrading in all sectors of the economy-and not just in the manufacturing sector, as the existing literature on productive capabilities have tended to focus on-Van Huelen and Abubakar on agriculture, Savona on services and natural resources industries. They also show that the recent expansion of the global value chains (GVCs) has not reduced the need for domestic productive capabilities upgrading efforts in developing countries, contrary to the widespread (but often implicit) assumption in the so-called GVC literature that those capabilities will be supplied by the lead firms. Van Huelen and Abubakar, LDM, and Savona all show how the expansion of GVCs have actually increased the need for the domestic supply of certain types of productive capabilities, while it may have reduced the need for some others.

The articles in the special issue also show that what happens in the site of production is vital to the process of upgrading of productive capabilities and the eventual transformation of the productive structure. Even many of the scholars who are interested in production and the development of productive capabilities have treated the sites of production (firms, farms, etc.) as 'black boxes' and have focussed more on the incentives (e.g. protective tariffs, subsidies, etc.) and the provision of collective inputs (e.g. infrastructure, state marketing services, etc.) than the learning dynamics and the investments in building productive capabilities that occur in productive enterprises. However, as for example AKT shows through detailed micro-data, firmlevel productive capabilities (made up of production capabilities and technological capabilities) play a crucial role in determining their performances.

The articles in the special issue show how we need to have a more sophisticated understanding of the process of productive capabilities than what is assumed in the existing literature. First, there are different types of productive capabilities. ACE emphasise the importance of collective productive capabilities-productive 
capabilities that are not contained in individuals (skilled workers, engineers, research scientists) but in organisational forms, organisational routines, organisational memories (e.g. company records), and collective institutions (e.g. laws and conventions that determine an economy's ability to restructure ailing enterprises). Developing different aspects of these productive capabilities require different approaches, both by producers but also by society (including the government). Second, the channels of productive capabilities accumulation, even when it comes to the same types of capabilities, vary. Even for productive capabilities development at the individual level, it may happen through 'natural' learning-bydoing but it can be done through deliberate investments in worker training. As for productive capabilities at the organisational level, it may result from (collective) learning-by-doing but often requires deliberate investments in better machines, management techniques, and research and development. The channels in which collective productive capabilities beyond the level of individual productive organisations have been extremely varied across countries, as shown by the existing literature and most clearly shown by LDM and GMR in this special issue.

Emphasising the importance of efforts at the sites of production does not mean that productive capabilities can be built only by the efforts of the producers. As emphasised by many studies before this special issue, such efforts need to be supported and forced by state intervention. Local contents requirement examined by LDM is a classic example of policy measures aimed at promoting (and compelling) the development of productive capabilities, but policies that we normally do not associate with the development of productive capabilities can have huge impacts on it. For example, Van Huelen and Abubakar shows how the increasing financialisation due to financial de-regulation has negatively affected the abilities of developing countries to upgrade their productive capabilities in cocoa production-an area of the economy that few people would link with financialisation. GMR shows that a competition policy that has failed to generate dynamic rivalry between the country's oligopolistic firms has hampered productive capabilities development in South Africa, unlike the competition policies of the East Asian 'miracle' economies.

The articles in the special issue also show how we need to change the ways in which we think about productive capabilities in light of changing technologies and emerging challenges. For example, ACL show how the development of the socalled 4IR technologies, which is leading to greater technological fusions, is making it more important for developing countries to acquire foundational capabilities, rather than acquiring productive capabilities related to any particular technology or particular industry. Savona points out that the development of productive capabilities in the modern service industries - mainly business services - are not something that are at odds with the development of those capabilities in those industries that business services are supposed to substitute-that is, natural resource industries and manufacturing industries. She shows that the development of productive capabilities in business services requires continued prosperity of those other industries that buy business services in order to produce material outputs, based on the development of their productive capabilities. Anzolin and Lebdioui show that, in the face of the comprehensive systemic challenge that climate change poses, we need to abandon 
the neat separation of the domains of consumption, production, and innovationand the capabilities required for each of them.

Far too long, the global development agenda, both academically and at the level of policy, has been dominated by perspectives that underplay (or even totally neglect) the importance of production, especially collective productive capabilities that are needed for its existence and development. Defining development as a matter of individual capabilities and efforts in areas of income, citizenship rights, and market opportunities, this discourse has only offered 'palliative' solutions-preferential access to some markets in rich countries (e.g. garment, agriculture), foreign aid, microfinance, conditional cash transfers, that do not involve fundamental transformation of underlying material and social structures of developing countries.

With the challenges posed by premature de-industrialisation, middle-income trap, financialisation, increasing precariousness of employment, climate change, and the Covid-19 pandemic, there is an increasing recognition that production needs to be brought back into the centre of development discourse. This special issue hopes to contribute to this revival by providing re-conceptualisations of some of the key theoretical issues, detailed empirical examinations of the process of developing productive capabilities, and discussions of new challenges, such as the so-called 4IR and climate change.

\section{References}

Amsden, A. 1989. Asia's next giant. New York: Oxford University Press.

Amsden, A. 1997. Editorial: Bringing production back in-Understanding Government's economic role in late industrialization. World Development 25: 469-480.

Andreoni, A. 2014. Structural Learning: Embedding discoveries and the dynamics of production. Structural Change and Economic Dynamics 29: 58-74.

Andreoni, A., and H.-J. Chang. 2017. Bringing production and employment back into development: Alice Amsden's legacy for a new developmentalist agenda. Cambridge Journal of Regions, Economy, and Society. https://doi.org/10.1093/cjres/rsw029.

Andreoni, A., and H.-J. Chang. 2019. The Political economy of industrial policy: Structural interdependencies, policy alignment and conflict management. Structural Change and Economic Dynamics 48: 136-50.

Andreoni, A., and R. Scazzieri. 2014. Triggers of change: Structural trajectories and production dynamics. Cambridge Journal of Economics 38 (6): 1391-1408.

Andreoni, A., and F. Tregenna. 2020. Escaping the middle-income technology trap: A comparative analysis of industrial policies in China, Brazil and South Africa. Structural Change and Economic Dynamics 54: 324-340.

Chang, H.-J. 1994. The political economy of industrial policy. Basingstoke: Macmillan.

Chang, H.-J. 2002. Kicking away the ladder: Development strategy in historical perspective. London: Anthem Press.

Chang, H.-J. 2010. Hamlet without the Prince of Denmark: How development has disappeared from today's "development" discourse. In Towards new developmentalism: Market as means rather than master, ed. S. Khan and J. Christiansen. Abingdon: Routledge.

Chang, H.-J., and A. Andreoni. 2020. Industrial policy in the 21st century. Development and Change 51 (2): 324-351.

Dosi, G. 1982. Technological paradigms and technological trajectories: A suggested interpretation of the determinants and directions of technical change. Research Policy 11 (3): 147-62.

Freeman, C. 1982. The economics of industrial innovation. London: Frances Pinter.

Fuso Nerini, F., Andreoni, A., Bauner, D., and Howells, M. 2016. Powering production: The case of the sisal fibre production in the Tanga region, Tanzania. Energy Policy 98: 544-556. 
Galbraith, J. 2012. Inequality and instability. A study of the world economy just before the great crisis. Oxford: Oxford University Press.

Hallegatte, S., J. Rogelj, M. Allen, et al. 2016. Mapping the climate change challenge. Nature Climate Change 6: 663-668.

Henson, S., U. Kambhampati, T. Mogues, et al. 2020. The development impacts of COVID-19 at home and abroad: Politics and implications of government action. European Journal of Devevelopment Research. https://doi.org/10.1057/s41287-020-00334-4.

Kaldor, N. 1972. The irrelevance of equilibrium economics. Economic Journal 82 (328): 1237-55.

Lall, S. 2001. Competitiveness, technology and skills. Cheltenham: Edward Elgar.

Lazonick, W., and J.-S. Shin. 2019. Predatory value extraction: How the looting of the business corporation became the US norm and how sustainable prosperity can be restored. Oxford: Oxford University Press.

Lee, K. 2013. Schumpeterian analysis of economic catch-up. Cambridge: Cambridge University Press.

Lema, R., R. Rabellotti, and P.G. Sampath. 2018. Innovation trajectories in developing countries: Co-evolution of global value chains and innovation systems. European Journal of Development Research 30: 345-363.

Lin, J., and H.-J. Chang. 2009. Should industrial policy in developing countries conform to comparative advantage or defy it? Development Policy Review 27: 483-502.

Nelson, R.R., and S.G. Winter. 1982. An evolutionary theory of economic change. Cambridge, MA: Belknap Press.

Nissanke, M., and J.A. Ocampo, eds. 2019. The Palgrave Handbook of development economics critical reflections on globalisation and development. Basingstoke: Palgrave Macmillan.

Pasinetti, L. 2007. Keynes and the Cambridge Keynesians: A 'Revolution in Economics' to be accomplished. Cambridge: Cambridge University Press.

Pavitt, K. 1984. Sectoral patterns of technical change: Towards a taxonomy and a theory. Research Policy 13 (6): 343-373.

Reinert, E., J. Gosh, and R. Kattel. 2018. Handbook of alternative theories of economic development. Cheltenham: Edward Elgar.

Robbins, L. 1935. An essay on the nature and significance of economic science. London: MacMillan and Co.

Scazzieri, R. 2019. Structural dynamics and evolutionary change. Structural Change and Economic Dynamics. https://doi.org/10.1016/j.strueco.2019.02.008.

Schumpeter, J. 1942. Capitalism, socialism and democracy. New York: Harper Collins.

Sen, A.K. 1999. Development as freedom. Oxford: Oxford University Press.

Toner, P. 1999. Main currents in cumulative causation theory. London: McMillan.

Wade, R. 1990. Governing the market. Princeton: Princeton University Press.

Publisher's Note Springer Nature remains neutral with regard to jurisdictional claims in published maps and institutional affiliations. 